\title{
A study on community expectation for cooperative behaviour among locals and migrants: a case study of an Okinawan village, Japan
}

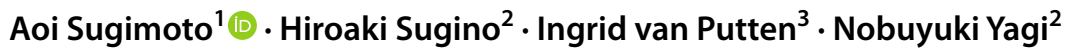

Received: 27 June 2020 / Accepted: 1 December 2021 / Published online: 15 December 2021

(c) The Author(s) 2021

\begin{abstract}
Despite the increasing need for local and migrant populations to cooperate in natural resource governance, little attention has been paid to community contexts that influence individual cooperative behavioural choices among them. The present study demonstrates this influence through quantitative and qualitative data obtained in Shiraho village, Okinawa, Japan. Externalised cooperative behaviour was significantly different between locals and migrants, and the residents' location in the social network was related to the level of cooperation, even though they had similar individual cooperative preferences. We find that people with dense social ties participate in community cooperation more than others, and that residents practise their cooperative behaviour in a way that fits community expectations: which was influenced by age and birth origin. Understanding the social context that guides individual behaviour for natural resource governance in a time when residential fluidity may keep increasing has relevance to other communities.
\end{abstract}

Keywords Locals and migrants $\cdot$ Coastal communities $\cdot$ Community cooperation $\cdot$ Natural resource governance $\cdot$ Social network

\section{Introduction}

An extensive body of literature has shown the importance of cooperation among local resource users to sustainably manage common-pool resources (Pinkerton 1989; Ostrom

Aoi Sugimoto

aois@affrc.go.jp

Hiroaki Sugino

hsuginoacademic@gmail.com

Ingrid van Putten

Ingrid.Vanputten@csiro.au

Nobuyuki Yagi

yagi@fs.a.u-tokyo.ac.jp

1 Fisheries Resources Institute, Japan Fisheries Research \& Education Agency, 2-12-4, Fukuura, Kanazawa-ku, Kanagawa prefecture, Yokohama 236-8648, Japan

2 Department of Global Agricultural Sciences, Graduate School of Agricultural and Life Sciences, The University of Tokyo, 7B-531, 1-1-1 Yayoi, Bunkyo-ku, Tokyo 113-8657, Japan

3 Division of Marine and Atmospheric Research, The Commonwealth Scientific and Industrial Research Organisation, Castray Esplanade, Battery Point, TAS 7004, Australia
1990; Ostrom et al. 1999; Jentoft 2000; Pretty and Ward 2001; Pretty 2003; Agrawal 2002; Carlsson and Berkes 2005; Acheson and Gardner 2011; Cinner et al. 2012; Basurto et al. 2013; Braaten 2014; Villasante and Österblom 2015). Cooperation can help prevent social dilemmas such as the overexploitation of natural resources. There is a broad consensus regarding the conditions that underpin cooperation in relation to natural resource governance, such as welldefined rules, monitoring ability, graduated sanctions and conflict resolution mechanisms (Baland and Platteau 1996; Lam 1998; Ostrom 1990; Agrawal 2002; Dietz et al. 2003). However, there are also several factors that can lead to cooperation failure: migration is recognized as a factor that can make cooperation in natural resource management more complex (Ostrom 1990; Bandiera et al. 2005). Migration can hamper cooperation due to unfamiliarity and a potential lack of mutual trust between locals and migrants (Palsson 1998; Ostrom et al. 1999; Katz 2000). Migration can make it more difficult to build a consensus due to differences in social and economic values, cultural norms and individual status (Cernea 1989; Blair 1996). Also, in coastal communities, migration has been one of the major causes of cooperation failure in natural resource governance (Dietz et al. 2003; Berkes et al. 2006; Glaser et al. 2012; Ferrol-Schulte 


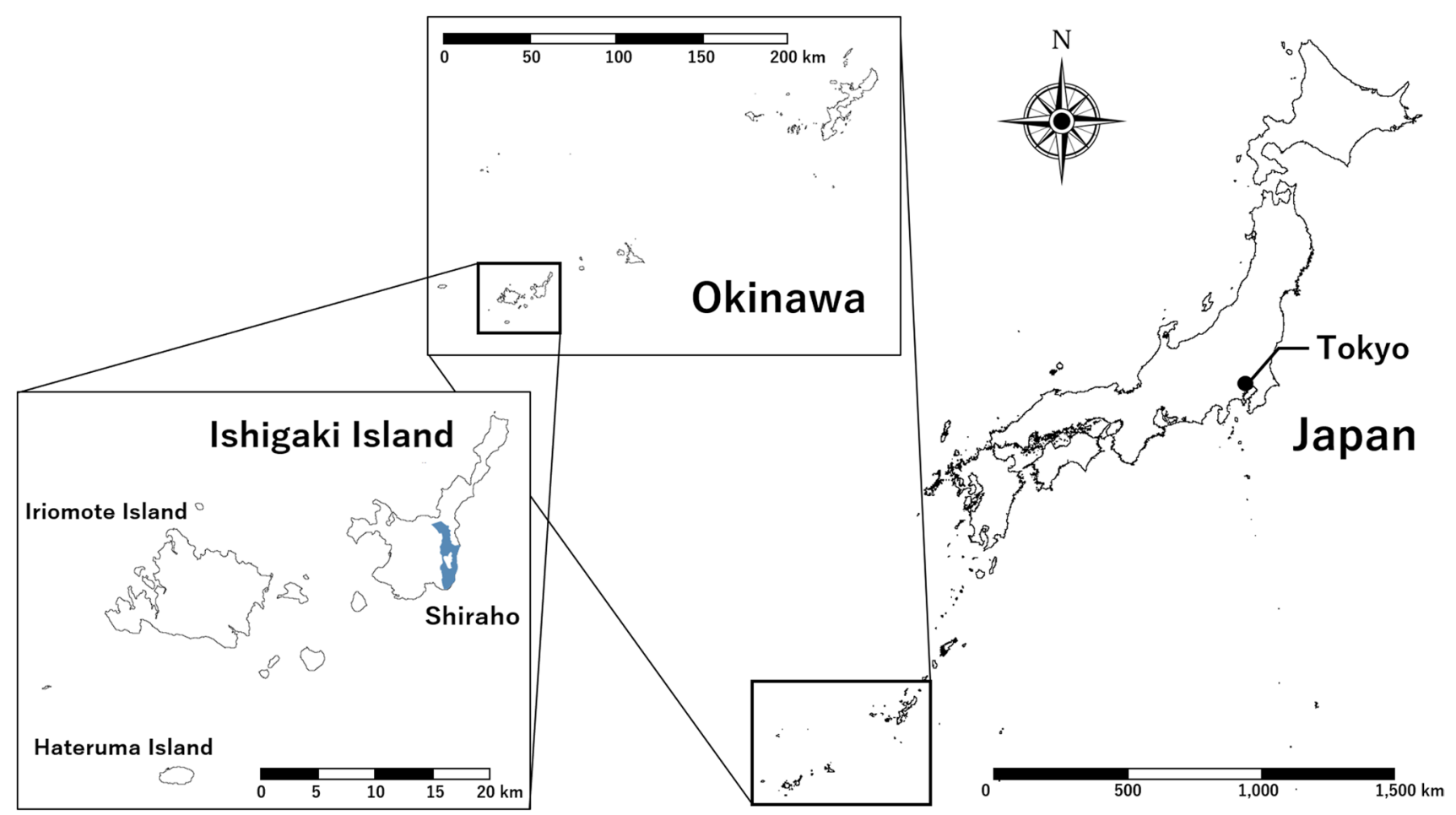

Fig. 1 Location of the case study site: Shiraho Village, on the east coast of Ishigaki Island

et al. 2013). However, it has been said that the exact effect of migration varies from place to place (Baker 1998; Molinas 1998; Vedeld 2000; Varughese and Ostrom 2001). Some studies indicate that there is a positive relationship between migrants' integration and their cooperative behaviour (Ostrom et al. 1999; Portes 1998; Curran 2002). Trust and social cohesion between locals and migrants is key for the integration of the two groups with consequent beneficial environmental outcomes (Portes 1998; Curran 2002; WIOMSA 2011). Some others have argued that there is not enough evidence to show that migrants contribute to either negative or positive outcomes (Sierra 1999; Begossi 1998; Cassels et al. 2005).

Previous works have examined cooperative behaviour through either laboratory experiments or field studies (e.g. Henrich 2000; Rustagi et al. 2010; Nettle et al. 2011). Both approaches have tended to focus on the externalised behaviour itself. Less attention has been paid to the expectation of the broader communities with respect to individual cooperative behavioural choices, with the exceptions of studies such as Waring (2011), Aswani et al. (2013) and Braaten (2014). However, given the increasing trend in human migration to coastal areas (Myers 2002; International Organization for Migration 2009; Black et al. 2011; Nicholls et al. 2011; Islam et al. 2014), it is important to deepen our understanding of the community's expectations around individual cooperative behavioural choices, and how the community context influences individual cooperative behaviours among local and migrant people. This research, therefore, aims to investigate community expectations and how they influence cooperative behaviour among locals and migrants by means of a case study in Shiraho Village, Okinawa, Japan.

\section{Methods}

\section{Study site description}

For the investigation, Shiraho Village, Okinawa, Japan, was selected as a case study site. Shiraho is located in the southeastern part of Ishigaki Island (Fig. 1) with a population of 1600 people in 755 households (Ishigaki City 2017). Okinawa is one of the four largest islands located in the most southern part of Japan. Ishigaki Island is located in the most western part of Okinawa and is part of Yaeyama archipelago. Prior to the establishment of Okinawa prefecture by Japan's Meiji government (1868-1912), Okinawa was not part of Japan but known as the Kingdom of Ryukyu, and after WWII, Okinawa was colonized by the USA until 1972. Since the time Okinawa was re-integrated as part of Japan, the Okinawa prefectural government has been trying to develop its economy by promoting tourism and advertising Okinawa as a "subtropical, exotic paradise island" to Japanese tourists (Tada 2004, 2008). Okinawa's historical 
background and socio-cultural context has attracted not only tourists but also new residents. New domestic migration has at times contributed to conflicts between Okinawan people and mainland Japanese (Sugimoto et al. 2017).

Shiraho community was selected firstly because about $40 \%$ of its population are migrants (Sugimoto 2016; Sugimoto et al. 2017). The migrants come from different parts of the country (inside and outside of Okinawa), ${ }^{1}$ but belong to the same linguistic and ethnic group. The latter made this community suitable for a detailed analysis of community expectations and their interaction with residents' cooperative behaviour. Secondly, we chose this area because there is a clear and strong recognition of "boundaries" with regard to the birth origin among community residents. The first wave of migration happened after 1771, when the community experienced a massive tsunami decimating as much as $95 \%$ of the population, with only 28 survivors remaining. After this extreme event, 418 migrants from Hateruma Island, located in the western part of Ishigaki Island, were forced to move to Shiraho following a policy of the Ryukyu government (Committee of Shiraho Village History Research 2009). Before and after World War II, the second wave of migrants came to the village to seek better livelihoods, from other parts of Okinawa (e.g. Ishihara and Aniya 1978). The most recent migrants are from mainland Japan; most moved to Shiraho Village after 1980 to take advantage of the pleasant climate (Tada 2004). This kind of domestic migration, searching for a better quality of life, has been observed all over Japan. Migration was also recently promoted through government policy as one of the solutions for tackling superaging issues in Japan (Sugimoto et al. 2020). Acceptance of migrants by the local community is not always easy because of dense social ties which are often closed among local people who have lived there over many generations, which is also the case in Shiraho. Descendants of the tsunami survivors and migrants from Hateruma Island constitute the local population; all belong to utaki-local places of worship that are considered centrally important to the spirit of the community (Nakamatsu 1990). Whether a resident is a local or a migrant can be easily distinguished by their family names. Both locals and migrants participate in daily community life but they are always able to recognize their respective heritage (Yoshida 2010; Sugimoto 2016; Sugimoto et al.

\footnotetext{
1 Japan has been implementing restrictive immigration policy for foreigners, but started expanding the employment of unskilled foreign workers through the revision of the Immigration Control and Refugee Recognition Law in 2018 due to serious aging issue (Song 2020). In Okinawa as well as other parts of the country, there are also foreign immigrants both before and after the above policy revision, but in fewer numbers compared to domestic migration, the latter of which this paper discusses. In the Shiraho community, there are some foreign immigrants who have lived there for many years. They were not included separately in this study because of the small number
}

2017). The distinction is particularly strong between people from Okinawa and from mainland Japan. For one example, a resident (migrant, $20 \mathrm{~s}$ ) whose parents moved there before her birth said that she had been recognized as a "mainland Japanese" even though she was born and raised on Ishigaki island. This distinction between local and migrant populations sometimes causes conflicts in the community. A local police officer (local, $40 \mathrm{~s}$ ) who has extensive experience interacting with community members, for example, said that many incidents at school, at the work place or in the household are related to personal conflicts between locals and migrants (mostly from mainland Japan). Despite this boundary, it has also been observed that some migrants are well-integrated and regarded as "real Shiraho residents", a term people tend to use to indicate locals. Conversely, some locals are said to be "not real Shiraho residents anymore", by not behaving according to the community's expectations (Sugimoto et al. 2017).

\section{Data collection and analysis}

\section{Questionnaire designing}

In this study, we applied both quantitative and qualitative social research methods and triangulated the information to increase internal validity (Neuman 2014; Yin 2017). At the basis of this research lies qualitative information which was available from fieldwork the first author had conducted from 2009 to 2015 . This qualitative data informed the development of the questionnaire in which quantitative information was collected. The quantitative data collection was carried out over 13 days in February 2016 in Shiraho Village. The qualitative data was utilized during the analysis enabling in-depth interpretation of the results. ${ }^{2}$

Since this paper aims to capture not only the externalised cooperation itself but also community's expectation and its influence on individual behaviours, the authors applied the following methods. At first, for measuring both externalised cooperation and individual intention to cooperate, two types of Likert-scale questions (Likert 1932; Boone and Boone 2012; Clason and Dormody 1994) were used: (a) degree of participation in community organisation ( $0-3$ scale for each of nine different organisations) as a measure of externalised community cooperation and (b) degree of cooperative

\footnotetext{
${ }^{2}$ Even after the quantitative data collection in 2016, the first author conducted fieldwork at the same study site for several different projects. Data obtained post-2016 from different study projects did not formally contribute to the interpretation of the current results (derived from the pre-2016 fieldwork); however, those separate projects did help in understanding the issue concerned.
} 
Table 1 Questionnaire items used in this study

\begin{tabular}{llll}
\hline ID & Item category & Questionnaire items and detail & Reference \\
\hline 1 & Participation into community org & 4 scale questions for 9 community organisations & Original \\
2 & Cooperative intention & I'm willing to help neighbours when they are in trouble & Original \\
& & We should help others if they are in trouble, regardless of the situa- & Hakoi and Takagi (1987) \\
& & tion one is facing at that time & Sugawara et al. (2006) \\
3 & Conformity & I am always worried if I may bother someone else & Sugawara et al. (2006) \\
& & It is shameful if I don't do something that everyone else is doing & Chavis et al. (2008) \\
4 & Sense of community & I can recognize most of the members of Shiraho village & Chavis et al. (2008) \\
& I am a person who is vital for Shiraho village & Original \\
5 & Emotional health & I often feel stressed in my daily life & Original \\
& I often feel stressed over working & Original \\
7 & Social network & Questions about kinship and daily contacts (Appendix 1) & Lamba and Mace 2011; \\
& Demographic variables & Age & Aswani et al. 2013
\end{tabular}

intention (1-5 scale for two questions) examining the degree of stated cooperative intention. Secondly, to explore how the community expectation influences individual behaviours, the authors assumed four constructs, namely: conformity, sense of community, emotional health and social network. Conformity is the tendency to conform around priorities given the collectivistic culture of Japanese rural communities (Cox et al. 1991; Yamauchi et al. 1995). Sense of community is an emotional bond that people have toward either territorial or relational community, which has been recognized as one of the important determinants of community cooperation (McMillan and Chavis 1986; Cuba and Hummon 1993; Morris 1996; Beggs et al. 1996; Manzo and Perkins 2006). Emotional health is regarded one element of well-being, including sense of personal/community security and life satisfaction (Kaplan-Hallam and Bennett 2018; Ban et al. 2019), and lastly, social network, often defined as patterns of relationships between individuals or groups, has been shown to influence collective action in natural resource governance (Granovetter 1973; Wasserman and Faust 1994; Bodin and Crona 2009; Barnes et al. 2016; Bodin 2017). For the former three constructs, we applied indices used in other studies (Hakoi and Takagi 1987; Sugawara et al. 2006; Chavis et al. 2008) as well as original items, by making sure these are easily understood by the participants. For measuring social network connections, questions about kinship and daily contact among residents were applied: the survey participants were asked to indicate their social networks in the community (see Appendix for the detail of questionnaire), through the local custom called kousai. In Okinawan communities including Shiraho, residents usually exchange and share various goods such as vegetables and seafoods with relatives, neighbours and friends in order to maintain social relationships (Sugimoto 2016). We also collected demographic variables: age, gender, origin and length of residence based on the past literature looking at the community cooperation among locals and migrants (Lamba and Mace 2011; Aswani et al. 2013). To ensure that the questions were understandable for participants and appropriate for gaining valid responses, we conducted pre-survey testing with several residents who were not included in the final survey (see Table 1 for overview of questionnaire items). For the item categories 2 to 5, some of the original question items required for hypothesis testing are used, and the wording has been modified to make the question items clear to local research participants. For these items, 2 questions were prepared for extracting each consciousness to reduce the measurement error.

\section{Sampling of the participants}

Participants were selected through quota sampling method according to the social structure of the community (Table 2). Firstly, the social relationships gained through previous fieldworks of the first author were used to invite participants, and then population segments that were less well represented were encouraged to participate. We note that some demographic groups are still over- or under-represented in our sample. For example, the survey sample had a higher number of participants in their thirties or forties than the village population. We attribute this to the fact that we selected participants mainly through community organisations, which are actively supported by residents in those age groups. The local population was also somewhat under-represented compared to the actual proportion. This could be owing to the 
Table 2 Survey participants' demographic structure (age, gender and birth origin ${ }^{\mathrm{a}}$ )

\begin{tabular}{llll}
\hline & & Participants & $\begin{array}{l}\text { Whole vil- } \\
\text { lage popula- } \\
\text { tion }\end{array}$ \\
\hline Gender (M:F, \%) & $64.4: 35.6$ & $49.4: 50.6$ & \\
Age (\%) & $20-29$ & 4.4 & 5.6 \\
& $30-39$ & 37.8 & 10.6 \\
& $40-49$ & 22.2 & 12.3 \\
& $50-59$ & 17.8 & 15.1 \\
& $60-69$ & 13.3 & 14.8 \\
& $\geq 70$ & 4.5 & 20.4 \\
& Total & 100 & 78.8 \\
Birth origin (\%) & Locals & 53.3 & 60.0 \\
& Migrants & 46.7 & 40.0 \\
& Total & 100 & 100 \\
\hline
\end{tabular}

${ }^{a}$ Data on birth origin were unavailable in official statistics, and numbers were obtained via an interview with a village hall representative (Sugimoto 2016)

local population generally being more reluctant regarding involvement in certain types of research activities conducted by external agents (e.g. scientists from outside the island). ${ }^{3}$ Our experience in recruiting participants demonstrates the social reality of this island community and random sampling would not necessarily have achieved a well-balanced representation. We have achieved increased validity by applying quantitative and qualitative methods and triangulating the data.

In this study, a field-based face-to-face questionnaire was implemented to gain insights into community expectations and their influence on cooperative behaviour among residents. For this kind of qualitative approach, researchers need to establish and maintain a rapport with the participants, especially as there were some questions about their social lives (e.g. social relationships, cooperative intentions and actual behaviours) which are sometimes delicate matters for participants' daily life in a small community. In this sense, ethical explanations in face-to-face conversations and appropriate follow-up during and after the survey were necessary. Due to the nature of the data collection approach and the abovementioned sensitivities, the time required to collect one person's data was significant and the sample size was commensurate with the time available to undertake this part of the research. Regarding the determination of a minimum

\footnotetext{
${ }^{3}$ As will be explained in more detail later, norms related to birth origin still shape the daily lives of residents. As a symbolic narrative showing this perception, one resident $(50 \mathrm{~s}$, male) said he was always trying to involve locals in his surveys, because without sufficient effort it would otherwise be regarded as "research by migrant from Japan mainland, and merely for migrants from Japan mainland".
}

but appropriate sample size, we anticipated that the main analysis will be a test of difference in the means of indicators between local and migrants. The minimum sample size can be determined with the following equation so that a significance determination can be made at a significance level of $5 \%$ with $80 \%$ detection power when the alternative hypothesis is correct (Norman and Strainer, 2003). By denoting the minimum sample size, the expected standard deviation and mean difference between 2 groups as $n, s$ and $d$, respectively, the formula can be expressed as:

$$
n=16 \frac{s^{2}}{d^{2}}
$$

When the expected standard deviation in the results obtained by the five-point Likert scale is 2 and the expected difference between the mean values of the two groups is 1.5 , the calculated minimum sample size for 1 group is 28 . When 2 groups were taken, the target number of sample size was set as 56 . As a result, 57 people participated in the interviews, of which 45 participants' responses were valid, providing adequate answers for statistical analysis (less than two N/A answers).

\section{Data analysis}

To begin with, the internal consistency for Likert-scale items within each variable was tested with Cronbach's alpha (Cronbach 1951; Cronbach \& Shavelson 2004). Cronbach's alpha was calculated to ensure internal consistency (Cortina, 1993). We did not use factor analysis because factor loadings and weights of each item vary by community or country. For the variables related to the social network, we first generated an undirected network sociogram with nodes as participants (or residents) and edges as their interactions (kinship and daily contacts). The information of each edge's direction and intensity (frequency) were omitted in this research as the focus is on the number of connections not the frequency. A series of network measures for each node was calculated focusing on centralities; degree centrality, betweenness centrality, closeness centrality and eigenvector centrality. These 4 variables are commonly used network centrality measures (Freeman 1979). The degree of each node refers to the number of edges that a node has (Wasserman and Faurst 1994). Betweenness centrality quantifies the number of times a node acts as a bridge along the shortest path between two other nodes (Newman 2010). Closeness centrality is calculated as the reciprocal of the sum of the length of the shortest paths between the node and all other nodes in the network, and so a node with high closeness centrality can reach other nodes within a small number of 
Table 3 Basic statistics for the Likert-scale questions for the 4 variables

\begin{tabular}{|c|c|c|c|c|c|c|}
\hline Item category & Questionnaire items and detail & Mean & $S . D$ & Min & Median & $\operatorname{Max}$ \\
\hline \multirow[t]{2}{*}{ Cooperative intention } & I'm willing to help neighbours when they are in trouble & 3.89 & 0.71 & 2 & 4 & 5 \\
\hline & $\begin{array}{l}\text { We should help others if they are in trouble, regardless of the } \\
\text { situation one is facing at that time }\end{array}$ & $\begin{array}{l}3.47 \\
\text { Cronbach's alpha: } 0.71\end{array}$ & 0.63 & 3 & 3 & 5 \\
\hline \multirow[t]{2}{*}{ Conformity } & I am always worried if I may bother someone else & 3.09 & 1.06 & 1 & 3 & 4 \\
\hline & It is shameful if I don't do something that everyone else is doing & $\begin{array}{l}2.62 \\
\text { Cronbach's alpha: } 0.69\end{array}$ & 1.05 & 1 & 3 & 5 \\
\hline \multirow[t]{2}{*}{ Sense of community } & I can recognize most of the members of Shiraho village & 2.38 & 0.91 & 1 & 2 & 5 \\
\hline & I am a person who is vital for Shiraho village & $\begin{array}{l}2.58 \\
\text { Cronbach's alpha: } 0.77\end{array}$ & 1.03 & 1 & 2 & 5 \\
\hline \multirow[t]{3}{*}{ Emotional health } & I often feel stressed in my daily life & 3.07 & 0.94 & 1 & 3 & 5 \\
\hline & \multirow[t]{2}{*}{ I often feel stressed over working } & 3.07 & \multirow[t]{2}{*}{1.23} & \multirow[t]{2}{*}{1} & \multirow[t]{2}{*}{3} & \multirow[t]{2}{*}{5} \\
\hline & & Cronbach's alpha: 0.77 & & & & \\
\hline
\end{tabular}

Fig. 2 Length of residents among locals and migrants

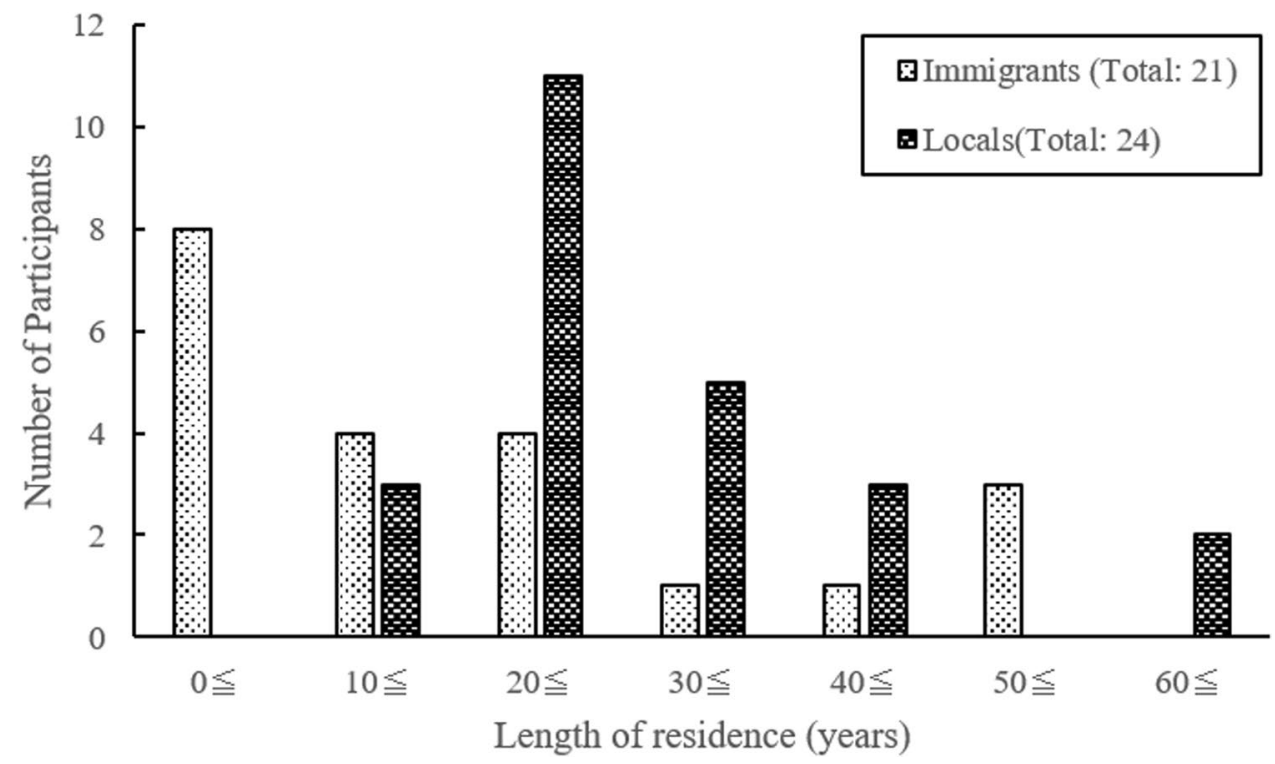

steps (Newman 2010). There is another measure called Eigenvector centrality which calculates the centrality of nodes connected to a targeted node, and this centrality represents the influence of a node in a network (Newman 2010).

A correlation analysis was conducted for the Likert-scale items, social network and demographic measures, using Spearman's rank correlation method (Spearman 1904). Next, we examined if there were any statistical differences in those measures between locals and migrants through Mann-Whitney test, a non-parametric approach which can be applied to smaller size samples and/or parametric assumptions such as normal distribution and equal variances. Lastly, we interpreted and discussed the community expectation and how it influenced cooperation among residents in detail, for which we also used the available qualitative data. $\mathrm{R}$ version 3.6.1 was used for Mann-Whitney test and calculation of Cronbach's $\alpha$ with "psych" package and generation of a sociogram with "igraph" packages. SPSS Statistics Version 25 (IBM) was used for correlation analysis.

\section{Results}

\section{Basic statistics of items from the questionnaire}

The internal consistency reliability for the Likert-scale items is shown in Table 3 as Cronbach's alpha. We regard the numbers as acceptable because these were close to 0.7 . With regard to the length of residence, perhaps as expected, many migrants had lived in the village of Shiraho less than 10 years, while most locals had lived in Shiraho for more than 20 years (Fig. 2). The level of participation in community organisations, degree centrality and betweenness 
Table 4 The basic statistics for the participation into community organisation, 4 Likert-based variables and 4 social network values

Table 5 Mann-Whitney test result between locals and migrants for the quantitative variables

\begin{tabular}{lllllll}
\hline Variables related to cooperation & Participation into community org & mean & s.d & median & min & max \\
& & 3.67 & 3.31 & 3 & 0 & 12 \\
& Cooperative intention & 7.36 & 1.15 & 7 & 5 & 10 \\
& Conformity & 5.71 & 1.84 & 6 & 2 & 9 \\
& Sense of community & 4.96 & 1.74 & 4 & 2 & 10 \\
& Emotional health & 6.13 & 1.98 & 6 & 2 & 10 \\
\hline \multirow{2}{*}{ Social network measures } & Degree centrality & 7.27 & 5.05 & 5 & 1 & 20 \\
& Betweenness centrality & 37.40 & 52.20 & 13.15 & 0 & 206.42 \\
& Closeness centrality & 0.00 & 0.00 & 0.00 & 0.00 & 0.00 \\
& Eigenvector centrality & 0.23 & 0.25 & 0.14 & 0.00 & 1 \\
\hline
\end{tabular}

\begin{tabular}{|c|c|c|c|c|c|c|}
\hline \multirow[t]{2}{*}{ variables } & \multicolumn{2}{|l|}{ Mean } & \multicolumn{2}{|l|}{ SD } & \multirow[t]{2}{*}{$U$} & \multirow[t]{2}{*}{$p$} \\
\hline & Locals & Migrants & Locals & Migrants & & \\
\hline Participation into community org & 4.75 & 2.43 & 3.27 & 2.96 & 143.00 & * \\
\hline Cooperative intention & 7.58 & 7.10 & 1.32 & 0.89 & 199.00 & $n . s$ \\
\hline Conformity & 5.46 & 6.00 & 1.96 & 1.70 & 292.00 & $n . s$ \\
\hline Sense of community & 5.71 & 4.14 & 1.83 & 1.31 & 129.50 & $* *$ \\
\hline Emotional health & 6.17 & 6.10 & 2.24 & 1.70 & 240.50 & $n . s$ \\
\hline Degree centrality & 9.75 & 4.43 & 5.46 & 2.46 & 86.00 & $* * *$ \\
\hline Betweenness centrality & 49.88 & 23.14 & 62.60 & 32.98 & 182.50 & $n . s$ \\
\hline Closeness centrality & 0.01 & 0.00 & 0.00 & 0.00 & 155.50 & $*$ \\
\hline Eigenvector centrality & 0.36 & 0.09 & 0.28 & 0.10 & 62.00 & $* * *$ \\
\hline
\end{tabular}

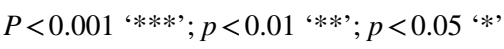

centrality are comparatively dispersed between local and migrant groups (Table 4). These results indicate that local and migrant groups differ in terms of length of residence, participation in community organisations and some types of social network centralities, further discussed below.

\section{Differences between locals and migrants for the quantified variables}

To statistically examine the differences between local and migrant groups, we conducted a Mann-Whitney test for 9 variables (excluding demographic variables), shown in Table 5. Degree $(U=86.00, p<0.001)$ and eigenvector centrality $(U=62.00, p<0.001)$ were significantly different between the two groups. Participation in community organisations $(U=143.00, p<0.01)$, sense of community $(U=129.50, p<0.01)$ and closeness centrality $(U=155.50$, $p<0.01$ ) were also significantly different. As previously indicated, participation in community organisations and several types of social network centralities (degree, eigenvector and closeness centrality) differed between the two groups. In addition, sense of community was also found to differ between the two groups. Participation in community organisations, as a "direct" measure of community cooperation, was significantly higher among locals than migrants. However, the two groups did not differ in their stated cooperative intention, and degree of conformity. This indicates that the externalised behavioural differences between them may not derive from their individual level preferences but from community-level expectations which influence individual cooperative behaviours. Differences in social network centralities (degree, eigenvector and closeness centrality) imply the following: the locals have more social ties, are more influential nodes and are more easily reachable ties than migrants in the community. It may be true that a greater sense of community is influencing the higher levels of participation in community organisations (McMillan and Chavis 1986; Cuba and Hummon 1993; Morris 1996; Beggs et al. 1996; Manzo and Perkins 2006). We will examine if these relationships are significant or not by the following correlation analysis, followed by the interpretation of what kind of communitylevel expectations influence individual cooperative behaviours, and how.

\section{Correlation analysis among all quantified variables}

Participation in community organisations was correlated with closeness centrality $(r=0.553, p<0.001)$, degree 
Table 6 Significant results of correlation analysis on three indicators for cooperation

\begin{tabular}{|c|c|c|c|c|c|c|c|c|c|c|c|c|}
\hline & \multicolumn{2}{|c|}{$\begin{array}{l}\text { Degree cen- } \\
\text { trality }\end{array}$} & \multicolumn{2}{|c|}{$\begin{array}{l}\text { Betweenness } \\
\text { centrality }\end{array}$} & \multicolumn{2}{|c|}{$\begin{array}{l}\text { Closeness central- } \\
\text { ity }\end{array}$} & \multicolumn{2}{|l|}{ Age } & \multicolumn{2}{|l|}{ Origin } & \multicolumn{2}{|c|}{$\begin{array}{l}\text { Emotional } \\
\text { health }\end{array}$} \\
\hline & $r$ & $p$ & $r$ & $p$ & $r$ & $p$ & $r$ & $p$ & $r$ & $p$ & $r$ & $p$ \\
\hline Participation into community org & 0.452 & $* *$ & 0.360 & $*$ & 0.553 & $* * *$ & -0.409 & $* *$ & 0.439 & $* *$ & -0.005 & $n . s$ \\
\hline Cooperative intention & 0.299 & * & 0.425 & $* *$ & 0.333 & $*$ & -0.047 & n.s & 0.145 & $n . s$ & 0.022 & n.s \\
\hline Conformity & 0.046 & $n . s$ & 0.036 & $n . s$ & -0.024 & $n . s$ & -0.282 & n.s & -0.107 & $n . s$ & -0.447 & $* *$ \\
\hline
\end{tabular}

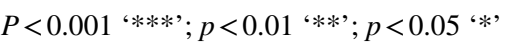

centrality $(r=0.452, p<0.01)$, origin $(r=0.439, p<0.01)$ and age $(r=-0.409, p<0.01)$ (Table 6$)$. Cooperative intention was correlated to betweenness centrality $(r=0.425$, $p<0.01)$; and conformity was correlated with emotional health $(r=-0.447, p<0.01)$. Closeness and degree centrality is significantly correlated to participation in community organisations. Combining this result with that of the previous section, it can be said that different levels of participation in community organisations between locals and migrants are related to their different levels of degree and closeness centralities.

\section{Discussion}

\section{What does 'expected cooperative behaviour' look like in the community?}

Even though we did not find significant differences in the cooperative intention and conformity between local and migrant people in our case study in Okinawa, we found a significant difference in their participation in community organisations. This means that externalised cooperative behaviour is different between locals and migrants, even though individual level cooperative intentions do not differ between them. Furthermore, participation in community organisations was significantly correlated to closeness and degree centrality. This may indicate that externalised cooperation is related to the person's location in the social network rather than individual (cooperative and conformity) preferences. Locals have significantly higher social network centralities (degree, eigenvector and closeness centrality) than migrant group, which is not unexpected considering the nature of the community. The kinship relations between the local people are very strong and start long before they are born and continue after they pass away. Many people describe such a community as 'the whole community is like a relative'. In addition to this close kinship, 'same year birth ties' are very strong in the community. Once people spend time together during elementary and/or junior high schools, even after graduation, they will have annual ceremonies and gatherings among the same-year groups. Perception of the way people should behave in the community is also strongly affected by age group. Although this work has not examined causal relationships (it can also be postulated that people acquire more social relationships by participating in community organisations), our interpretation is that the close social ties (including kinship) should result in people with these dense ties participating in the community cooperation more than others. Our results also show that the Shiraho community consists of dense and homophilous (McPherson et al. 2001; Barnes et al. 2016) social networks mainly dominated by the locals, where migrant groups appear to be more 'marginal' in the decision-making process. Previous research has examined the relationships between social networks and natural resource governance (Bodin and Crona 2009; Barnes et al. 2016; Bodin 2017; Mbaru and Barnes 2017), while this work focused more on community-level network structure and a qualitative interpretation of how it influences cooperation among residents in a specific rural community.

Also, of note in this work is that the results were different from previous works (Lamba and Mace 2011; Aswani et al. 2013) regarding the relationship between age and community cooperation: We found a negative correlation between age and cooperation. We interpret this as owing to the community's expectation of proper behaviour among residents according to age: more specifically, younger ( $20 \mathrm{~s}-40 \mathrm{~s}$ ) residents should contribute to the community more than other generations. As explained earlier, perceptions of the way people should behave in the community is strongly affected by their age group, and the community's expectation are sometimes perceived as a "burden" among younger generations. One resident described it as "we have to work very hard, like a slave, when we are younger in the community" (local, $30 \mathrm{~s}$ ); another described it as "older residents have to stop behaving in a selfish way and forcing their thoughts on younger ones" (local, $30 \mathrm{~s}$ ). Hence, we can see that there is a strong community expectation that younger residents should cooperate and contribute significantly to the community, which could cause the negative relationship between age and participation in community organisations. Younger residents are cooperating more than others according to community expectations, while at the same time, they are struggling 
with the social pressure to contribute to the community as indicated by the negative relationship between conformity and emotional health.

Where residents originated from was also found to have significant impact on participation in community organisations, which also can be explained by the community expectation. A resident (migrant, $50 \mathrm{~s}$ ) explained that they were always trying "not to stand out too much" in the community as part of their active participation in and contribution to the community. This is because there is a "silent consensus" that locals should receive the highest respect, followed by the migrants from other Okinawan islands, then migrants from the Japanese mainland community. The same migrant also said, "I always make statements where I carefully consider the 'balance' as a migrant from Japan mainland, when I attend important community meetings." Another resident (50 s, migrant), also from the Japanese mainland, said that they were more careful to ensure a 'better seat' when attending community meetings as they were getting older. In Japanese culture, seating arrangements are usually dictated by an underlying social status, with older people having higher status than those who are younger and locals having higher status than migrants. As the resident gets older, their social standing increases. But the respondent said that since he is still considered a migrant, he must be careful not to take 'too good' a seat. He said, "I've started sitting in the appropriate places as I'm kind of an elder in the community now. It would be strange if I keep sitting in the least important seats, you know". The residents' narratives show that the community's expectation is shaped by age and birthplace: residents should behave appropriately according to both social factors.

The results indicate that individual residents practise their cooperative behaviour in a way that fits community expectations according to their age and birth origin, which is also influenced by their position in the social network. In local, especially rural communities, there are usually strong collective expectations that influence individual behaviours. Hence, it is not sufficient that we only focus on the externalised individual behaviours; instead, we need to focus more on the social context that guides individual behaviour in order to better understand community-level cooperation. Just as communities are not merely aggregates of individual parts (Jentoft et al. 1998), community-level cooperation is also not merely an aggregate of individual-level cooperative behaviours.

\section{Limitation of the present work and future study avenues}

This work has deepened our understanding of the community's expectations around individual cooperative behavioural choices, and how the community context influences individual cooperative behaviours among local and migrant people. The authors acknowledge that the sample size is relatively small and is a limitation of this present work (but see "Sampling of the participants"). The research is also specific to the Japanese cultural context and cannot be easily generalised to other cultures. Hence, one thing future works need to address is cross-cultural examination of the finding of this work. The quantitative method such as closed questionnaire items and the analytical methods utilized in this work should be particularly useful when considering the expansion of similar investigation into other geographical/ cultural settings. As explained earlier, this work paid extra attention to building and maintaining rapport with the participants through follow-up semi-structured interviews during and after the survey. This approach ensured greater reliability of responses which were less biased than might have been in a closed questionnaire design based on researchers' interests. Such reliability, however, could be sacrificed when attempting to scale up the survey in terms of sample size and geographical coverage. The local relationships and rapport between researchers and respondents can then become potentially more difficult to maintain. Furthermore, it will also be worth investigating if the community expectations related to age and birth origin, found by this work, could presently be changing in Japanese rural communities including Okinawan islands. Contemporary dynamics of this kind of community expectations could certainly impact numerous aspects of social lives, including the decision-making process in and outside of the local community. It will be potentially invaluable to examine such dynamics among multiple study sites with different social/economic/cultural status.

\section{Conclusion}

The present study revealed that there is no difference in the intention to cooperate and conform between local and migrant groups in our case study in Okinawa, Japan. Moreover, the way individual residents of Okinawa practise their cooperative behaviour fulfils community expectations. But externalised cooperative behaviour, such as participation in community organisation, is more strongly related to the people's position in social networks than to individual preferences. The tension between intentions and externalised cooperative behaviour, and the difference between migrant populations and local people in this regard, is important for natural resource governance in the time when residential fluidity may keep increasing.

Supplementary Information The online version contains supplementary material available at https://doi.org/10.1007/s40152-021-00254-x.

Funding This work was supported by the JSPS KAKENHI (Grant number 4403) "New Ocean Paradigm on its Biogeochemistry, Ecosystem, and Sustainable Use". 


\section{Declarations}

Conflict of interest The authors declare no competing interests.

Open Access This article is licensed under a Creative Commons Attribution 4.0 International License, which permits use, sharing, adaptation, distribution and reproduction in any medium or format, as long as you give appropriate credit to the original author(s) and the source, provide a link to the Creative Commons licence, and indicate if changes were made. The images or other third party material in this article are included in the article's Creative Commons licence, unless indicated otherwise in a credit line to the material. If material is not included in the article's Creative Commons licence and your intended use is not permitted by statutory regulation or exceeds the permitted use, you will need to obtain permission directly from the copyright holder. To view a copy of this licence, visit http://creativecommons.org/licenses/by/4.0/.

\section{References}

Acheson, J., and R. Gardner. 2011. The evolution of the Maine lobster V-notch practice: Cooperation in a prisoner's dilemma game. Ecol Soc 16: 41

Agrawal A (2002) Common resources and institutional stability. In: Ostrom E (ed) The Drama of the Commons, National Academy Press, Washington.

Aswani, S., G. Gurney, S. Mulville, J. Matera, and M. Gurven. 2013. Insights from experimental economics on local cooperation in a small-scale fishery management system. Global Environ Chang 23: 1402-1409. https://doi.org/10.1016/j.gloenvcha.2013.08.003.

JM Baker 1998 The effect of community structure on social forestry outcomes: Insights from Chota Nagpur India. Mt Res Dev 51-62 https://doi.org/10.2307/3673867

Baland, J.M., and J.P. Platteau. 1996. Halting degradation of natural resources: Is there a role for rural communities? Oxford: Clarendon Press.

Ban N C, Gurney, G G, Marshall N A, Whitney C K, Mills M, Gelcich, S, Bennett N J, Meehan M C, Butler C,

S Ban TC Tran ME Cox SJ Breslow 2019 Well-being outcomes of marine protected areas Nature Sustainability 524-532 https://doi. org/10.1038/s41893-019-0306-2

Bandiera, O., I. Barankay, and I. Rasul. 2005. Cooperation in Collective Action. Econ Trans 13: 473-498. https://doi. org/10.1111/j.1468-0351.2005.00228.x.

Barnes, M.L., J. Lynham, K. Kalberg, and P. Leung. 2016. Social networks and environmental outcomes. P Natl Acad Sci USA 113: 23. https://doi.org/10.1073/pnas.1523245113.

Basurto, X., A. Bennett, A. Weaver, S. Rodriguez-Van Dyck, and J.S. Aceves-Bueno. 2013. Cooperative and noncooperative strategies for small-scale fisheries' self-governance in the globalization era: Implications for conservation. Ecol Soc 18: 38. https://doi. org/10.5751/ES-05673-180438.

Beggs, J.J., J.S. Hurlbert, and V. Haines. 1996. Community attachment in a rural setting: A refinement and empirical test of the systemic model. Rural Soc 61: 407-426. https://doi. org/10.1111/j.1549-0831.1996.tb00626.x.

Begossi A (1998) Resilience and neo-traditional populations: the caicaras (Atlantic Forest) and caboclos (Amazon, Brazil). In Berkes F, Folke C (eds.), Linking social and ecological systems: management practices and social mechanisms for building resilience. Cambridge University Press, Cambridge.

Berkes, F., T. Hughes, R. Steneck, J. Wilson, D. Bellwood, B. Crona, and B. Worm. 2006. Globalization, roving bandits, and marine resources. Science 311: 1557-1558. https://doi.org/10.1126/ science. 1122804

Black, R., W.N. Adger, N. Arnell, S. Dercon, A. Geddes, and D. Thomas. 2011. The effect of environmental change on human migration. Global Environ Chang 21: S3-S11. https://doi. org/10.1016/j.gloenvcha.2011.10.001.

Blair, H.W. 1996. Democracy, equity, and common property resource management in the Indian Subcontinent. Dev Change 27: 475499. https://doi.org/10.1111/j.1467-7660.1996.tb00600.x.

Bodin, O., and B.I. Crona. 2009. The role of Social networks in natural resource governance: What relational patterns make a difference? Global Environ Chang 19 (3): 366-374. https://doi.org/10.1016/j. gloenvcha.2009.05.002.

Bodin O (2017) Collaborative environmental governance: achieving collective action in social-ecological systems. Science 357(6352). https://doi.org/10.1126/science.aan1114

Bontempo, R., S.A. Lobel, and H.C. Triandis. 1990. Compliance and value internalization in Brazil and the US: Effects of allocentrism and anonymity. J Cross Cult Psychol 21: 200-213. https:// doi.org/10.1177/0022022190212004.

Braaten, R.H. 2014. Land rights and community cooperation: Public goods experiments from Peru. World Devel 61: 127-141. https://doi.org/10.1016/j.worlddev.2014.04.002.

Carlsson, L., and F. Berkes. 2005. Co-management: Concepts and methodological implications. J Environ Manag 75: 65-76. https://doi.org/10.1016/j.jenvman.2004.11.008.

Cassels, S., S.R. Curran, and R. Kramer. 2005. Do migrants degrade coastal environments? Migration, natural resource extraction and poverty in North Sulawesi, Indonesia. Human Ecol 33: 329-363. https://doi.org/10.1007/s10745-005-4142-9.

Cernea MM (1989) User groups as producers in participatory afforestation strategies. The World Bank. [WWW Document]. Retrieved from http://documents.worldbank.org/curated/ en/742751468739271216/pdf/multi-page.pdf

Chavis DM, Lee KS, Acosta JD (2008) The sense of community (SCI) revised: the reliability and validity of the SCI-2. Presented at the 2nd International Community Psychology Conference, Lisbon, Portugal.

Cinner, J.E., X. Busarto, P. Fidelman, J. Kuange, R. Lahari, and A. Mukminin. 2012. Institutional designs of customary fisheries management arrangements in Indonesia, Papua New Guinea, and Mexico. Marine Policy 36: 278-285. https://doi.org/10. 1016/j.marpol.2011.06.005.

Committee of Shiraho Village History Research (2009) History of Shiraho Village. Committee of Shiraho Village History Research, Okinawa.

Cortina, J.M. 1993. What is coefficient alpha? An examination of theory and applications. J Appl Psychol 78 (1): 98-104. https:// doi.org/10.1037/0021-9010.78.1.98.

Cox, T.H., S. Lobel, and P.L. McLeod. 1991. Effects of ethnic group cultural differences on cooperative and competitive behavior on a group task. Acad Manag J 34: 827-847. https://doi.org/ $10.2307 / 256391$.

Cronbach, L. 1951. Coefficient alpha and the internal structure of tests. Psychometrika 16: 297-334. https://doi.org/10.1007/ BF02310555.

Cronbach, L.J., and R.J. Shavelson. 2004. My current thoughts on coefficient alpha and successor procedures. Educ Psychol Meas 64: 391-418.

Cuba, L., and D.M. Hummon. 1993. A place to call home: Identification with dwelling, community, and region. Sociol Quart 34: 111-131. https://doi.org/10.1111/j.1533-8525.1993.tb00133.x.

Curran, S. 2002. Migration, social capital, and the environment: Considering migrant selectivity and networks in relation to coastal ecosystems. Pop Devel Rev 28: 89-125. 
Dietz, T., E. Ostrom, and P.C. Stern. 2003. The struggle to govern the commons. Science 302: 1907-1912. https://doi.org/10.1126/ science.1091015.

Ferrol-Schulte, D., M. Wolff, S. Ferse, and M. Glaser. 2013. Sustainable livelihoods approach in tropical coastal and marine socialecological systems: A review. Marine Pol 42: 253-258. https:// doi.org/10.1016/j.marpol.2013.03.007.

Freeman, L.C. 1978. Centrality in social networks conceptual clarification. Social Networks 1 (3): 215-239. https://doi.org/10.1016/ 0378-8733(78)90021-7.

Glaser, M., P. Christie, K. Diele, L. Dsikowitzky, S. Ferse, I. Nordhaus, and C. Wild. 2012. Measuring and understanding sustainability-enhancing processes in tropical coastal marine socialecological systems. Curr Opin Env Sust 4: 300-308. https://doi. org/10.1016/j.cosust.2012.05.004.

Granovetter, M. 1973. The strength of weak ties. Am J Sociol 78 (6): $1360-1380$.

Hakoi H, Takagi O (1987) A comparative study of normative attitude toward helping between the different groups of sex, age and generation. Japan J Soc Psychol, 3:39-47. https://doi.org/10.14966/ jssp.KJ00003725045

International Organization for Migration (2009) Migration, environment and climate change: assessing the evidence. [WWW Document]. Retrieved from https://publications.iom.int/system/files/ pdf/migration_and_environment.pdf

Ishigaki City (2017) Statistical report No. 40. [WWW Document] Retrieved from http://www.city.ishigaki.okinawa.jp/home/ kikakubu/kikaku/toukei.htm

Ishihara, M., and M. Aniya. 1978. An analysis of the actual conditions of settlement in the Yaeyama Islands with reference to changes in reclamation, migration, and administration. Bull Dept Soc, Okinawa Interntl Univ 6: 151-217.

Islam, M.M., S. Sallu, K. Hubacek, and J. Paavola. 2014. Migrating to tackle climate variability and change? Insights from coastal fishing communities in Bangladesh. Clim Chang 124: 733-746. https://doi.org/10.1007/s10584-014-1135-y.

Jentoft, S. 1998. Social theory and fisheries co-management. Marine Policy 22 (4-5): 423-436.

Jentoft, S. 2000. The community: A missing link of fisheries management. Marine Policy 24: 53-59. https://doi.org/10.1016/S0308597X(99)00009-3.

Katz, E.G. 2000. Social capital and natural capital: A comparative analysis of land tenure and natural resource management in Guatemala. Land Econ 76: 114-132. https://doi.org/10.2307/3147261.

Kaplan-Hallam, M., and N.J. Bennett. 2018. Adaptive social impact management for conservation and environmental management. Conserv Biol 32 (2): 304-314. https://doi.org/10.1111/cobi. 12985.

Lam, W.F. 1998. Governing irrigation systems in Nepal: Institutions, infrastructure, and collective action. Oakland: Institute for Contemporary Studies Press.

Lamba, S., and R. Mace. 2011. Demography and ecology drive variation in cooperation across human populations. PNAS 108: 1442614430. https://doi.org/10.1073/pnas.1105186108.

Likert,. 1932. A technique for the measurement of attitudes. New York: Archives of Psychology.

Boone, Boone. 2012. Analyzing Likert Data. J Extention 66 (8): 1456-1466.

Clason, Dormody. 1994. Analyzing data measured by individual Likert-type items. J Agri Edu 35 (4): 31-35.

Manzo, L.C., and D.D. Perkins. 2006. Finding common ground: The importance of place attachment to community participation and planning. J Plan Lit 20: 335-350. https://doi.org/10.1177/08854 12205286160

Marshall, N.A. 2007. Can policy perception influence social resilience to policy change? Fisheries Res 86: 216-227.
DW McMillan DM Chavis 1986 Sense of community: A definition and theory J Comm Psych 14623 https://doi.org/10.1002/15206629(198601)14:1<6::AID-JCOP2290140103>3.0.CO;2-I

Molinas, J.R. 1998. The impact of inequality, gender, external assistance and social capital on local-level collective action. World Devel 26: 413-431. https://doi.org/10.1016/ S0305-750X(97)10066-3.

Morris, E.W. 1996. Community in theory and practice: A framework for intellectual renewal. J Plan Lit 11: 127-150.

Myers, N. 2002. Environmental refugees: A growing phenomenon of the 21st century. Philos T R Soc B 357: 609-613. https://doi.org/ 10.1098/rstb.2001.0953.

Nakamatsu Y (1990a) Spirits and the village. Shinsensha, Tokyo.

Nettle, D., A. Colléony, and M. Cockerill. 2011. Variation in cooperative behaviour within a single city. PLOS ONE 6: e26922. https://doi.org/10.1371/journal.pone.0026922.

Neuman WL (2014) Social research methods: qualitative and quantitative approaches. Seventh Edition Pearson Education Limited.

Newman, M.E.J. 2010. Networks: An introduction. Oxford, UK: Oxford University Press.

Nicholls, R.J., N. Marinova, J.A. Lowe, Brown S. Vellinga, and P, de Gusmão D, Tol RSJ,. 2011. Sea-level rise and its possible impacts given a "beyond $4{ }^{\circ} \mathrm{C}$ world" in the twenty-first century. Philos T R Soc B 369: 161-181. https://doi.org/10.1098/rsta. 2010.0291].

Norman, G. R., \& Streiner, D. L. (2003). PDQ statistics. Hamilton, Ont: B.C. Decker.

Ostrom, E. 1990. Governing the commons: The evolution of institutions for collective action. New York: Cambridge University Press.

Ostrom, E., J. Burger, C. Field, R. Norgaard, and D. Policansky. 1999. Revisiting the commons: Local lessons, global challenges. Science 284: 278-282. https://doi.org/10.1126/science.284.5412.278.

Palsson, G. 1998. Learning by fishing: Practical engagement and environmental concerns. In Linking Social and Ecological Systems, ed. F. Berkes and C. Folke, 48-66. Cambridge: Cambridge University Press.

Pinkerton, E., ed. 1989. Cooperative management of local fisheries: New directions for improved management and community development. Vancouver: University of British Columbia Press.

Pollnac, R.B., and R.S. Pomeroy. 2005. Factors influencing the sustainability of integrated coastal management projects in the Philippines and Indonesia. Ocean Coast Manag 48: 233-251.https://doi. org/10.1016/j.ocecoaman.2005.04.003.

Portes, A. 1998. Social capital: Its origins and applications in modern sociology. Ann Rev Soc 22: 1-24. https://doi.org/10.1146/annur ev.soc.24.1.1.

Pretty, J. 2003. Social capital and the collective management of resources. Science 302: 1912-1914. https://doi.org/10.1126/scien ce. 1090847.

Pretty, J., and H. Ward. 2001. Social capital and the environment. World Devel 29: 209-227. https://doi.org/10.1016/S0305750X(00)00098-X.

Rustagi, D., S. Engel, and M. Kosfeld. 2010. Conditional cooperation and costly monitoring explain success in forest commons management. Science 330: 961-965. https://doi.org/10.1126/science. 1193649.

Sierra, R. 1999. Traditional resource-use systems and tropical deforestation in a multiethnic region in Northwest Ecuador. Environ Conserv 26: 136-145.

Spearman, C. 1904. The proof and measurement of association between two things. Am J Psychol 15 (1): 72-101. https://doi.org/10.2307/ 1412159.

Sugawara, K., N. Nagahusa, J. Sasaki, A. Fujisawa, and R. Azami. 2006. The adolescents' annoying acts and feelings of shame: The association with five behavioral standards in public. Seishinn Women University Ronnso 107: 59-77 ((in Japanese)). 
Song, Jiyeoun. 2020. The political dynamics of Japan's immigration policies during the Abe Government*. Pacific Focus 35 (3): 613-640.

A Sugimoto 2016 Fish as a "bridge" connecting migrant fishers with the local community: Findings from Okinawa Japan. Marit Stud 15 https://doi.org/10.1186/s40152-016-0046-0

A Sugimoto H Sugino N Yagi 2017 Capturing the representation of the rural community from the perspective of local residents in Okinawan island: Implication for building social cohesion among locals and migrants in rural communities J Coastl Zone Stud 30 3 (in Japanese)

Sugimoto, A., H. Sugino, S. Ueda, and K. Funasaka. 2020. Empirical analysis on an "associated population" in contemporary Japanese society: From a national level survey results. J Coastl Zone Stud 33: 3 ((in Japanese)).

Tada O (2004) Emergence of the Okinawan image: cultural studies of the Blue Ocean.: Toyokeizai shimpo-sha, Tokyo.

Tada O (2008) Travelling the Okinawan image. Chuokoron-shinsha, Tokyo (in Japanese)

Varughese, G., and E. Ostrom. 2001. The contested role of heterogeneity in collective action: Some evidence from community forestry in Nepal. World Devel 29: 747-765.

Vedeld, T. 2000. Village politics: Heterogeneity, leadership and collective action. J Devel Stud 36: 105-134. https://doi.org/10.1080/ 00220380008422648.

Villasante, S., and H. Österblom. 2015. The role of cooperation for improved stewardship of marine social-ecological systems in
Latin America. Ecology and Society 20: 8-11. https://doi.org/10. 5751/ES-05949-200108.

Waring T (2011) Ethnic forces in collective action: diversity, dominance, and irrigation in Tamil Nadu. Ecol Soc 16(4). https://doi. org/10.5751/ES-04265-160401

S Wasserman K Faust 1994 Structural analysis in the social sciences SocNetw Anal Meth Appl Cambridge Univ Press https://doi.org/ 10.1017/CBO9780511815478

WIOMSA (2011) Migrant fishers and fishing in the Western Indian Ocean: socio-economic dynamics and implications for management. Final Report of Commissioned Research Project MASMA/ $\mathrm{CR} / 2008 / 02$

Yin RK (2017) Case study research and applications: design and methods. Sixth Edition. SAGE Publications.

Yoshida, K. (2010) Rethinking village communities in Okinawa: focusing on interactions between newcomers and locals in the northern part of Ishigaki Island.. Jinbun Gakuho (Journal of Science and Humanities), Department of Humanities, Tokyo Metropolitan University 423: 71-102 (in Japanese).

Publisher's Note Springer Nature remains neutral with regard to jurisdictional claims in published maps and institutional affiliations. 